\title{
Implementation of Forensic Analysis Procedures for WhatsApp and Viber Android Applications
}

\author{
Auqib Hamid Lone \\ Department of Computer \\ Science and Engineering, \\ Jamia Hamdrad \\ New Delhi, India
}

\author{
Firdoos Ahmad Badroo \\ Department of Computer \\ Science and Engineering, \\ Jamia Hamdrad \\ New Delhi, India
}

\author{
Khairaj Ram Chudhary \\ Department of Computer \\ Science and Engineering, \\ Jamia Hamdrad \\ New Delhi, India
}

\author{
Aqeel Khalique \\ Department of Computer Science and Engineering, \\ Jamia Hamdrad \\ New Delhi, India
}

\begin{abstract}
Communication in today's world is mostly dependent on mobile phones allowing users to exchange messages, ideas, videos and audios. Numerous instant messengers are available for mobile devices which are better alternative over SMS technology. However, increased use of instant messengers also gave rise to its negative impact including unwanted activities pertaining to cyber crimes. WhatsApp and Viber are mostly used instant messengers on Android mobile devices. In this paper, we perform forensic analysis procedures to obtain artifacts of WhatsApp and Viber applications. During analysis, we focus on artifacts such as messages, contacts, chat history, attachments etc. from the memory of mobile device. We present our research findings after implementation of forensic procedures using freely available tools and software. The artifacts obtained during analysis are relevant to use as evidences in court of law against any criminal incident.
\end{abstract}

\section{General Terms}

Android Forensic, Instant Messenger Forensics.

\section{Keywords}

Android Forensics, Instant Messenger Forensics, Viber Forensics, WhatsApp Forensics.

\section{INTRODUCTION}

Communication is a process of connecting people to exchange facts, ideas, impressions or feelings. Communication system requires sender, receiver and a medium. In today's world, several medium are present to conduct effective communication. Technology has given birth to a new communication medium known as wireless communication. Mobile phones use wireless communication media to transmit and receive audio, video or text messages across the world using wireless connection of service providers. One of the required aspects of communication is non-repudiation, where sender cannot deny sending or transmitting intended message to receiver. Excessive use of communication over mobile phones leads to non-repudiation in certain instances where a risk is involved with sender. Most often in litigation and prosecution cases of financial and criminal activities, accused personnel may deny or may not be available for investigation. In such instances, technology helps us to investigate into the matter or testify the true facts to bring digital evidence acceptable in court of law. Digital or cyber forensic is the process of collecting, preserving, analyzing and presenting the digital evidence which is legally acceptable. In digital forensic, analysis is done on data available pertaining to the specific case. Therefore, if there is a heap of data, more chances are to extract fruitful evidences or information out of the heap.In this paper, we implement forensic analysis procedures on two widely used instant messengers namely WhatsApp and Viber. We have organized the paper in the following order: In Section 2 introduces Technology review for Digital Forensics. In Section 3, we study database schema of WhatsApp and Viber applications on Android. In Section 4, we implement the methodologies for analyzing artifacts of WhatsApp and Viber. In Section 5, we present results based on our research findings. In Section 6, we conclude our work and present future scope in digital forensic over mobile phones.

\section{TECHNOLOGY REVIEW FOR DIGITAL FORENSICS}

\subsection{Android Application Data Storage}

Android is the world's most popular mobile platform having a large user base. Android provides several options to save persistent application data [1]. Location of data storage depends on accessibility between applications and user and size of applications. Table 1 shows Android Application Data Storage options with mapped with several parameters such as file type, data type, location, access level and their forensic use [2].

\subsection{WhatsApp Messenger}

WhatsApp is a cross-platform instant messaging application available for Symbian, Asha, Windows Mobile, Android, iOS and Blackberry operating systems [3]. WhatsApp was developed in 2009 by Brian Acton and Jan Koum and was acquired by Facebook in 2014 . WhatsApp has more than 900 million registered users and handling 64 billion messages per day. WhatsApp uses $\mathrm{WiFi}$ or mobile internet plan for communicating with other users. WhatsApp is available for free during the first year and later a nominal subscription fee is charged annually. WhatsApp can auto sync to the phone address book allowing unlimited message to the contacts using WhatsApp application. Messages also include attachments to share multimedia like audios, videos, locations, images etc. WhatsApp has started calling feature to the 
contacts using WhatsApp application. WhatsApp Web is launched to give user device flexibility for running WhatsApp from desktop PC using internet browser. Thus, WhatsApp is an important application for obtaining vital data or information in an hour of need to cyber forensic analyst [4].

Table 1. Android Application Data Storage

\begin{tabular}{|c|c|c|c|c|c|}
\hline \multicolumn{6}{|c|}{ Android Application Data Storage Options } \\
\hline & $\begin{array}{c}\text { Shared } \\
\text { Preference }\end{array}$ & $\begin{array}{l}\text { Internal } \\
\text { Storage }\end{array}$ & $\begin{array}{l}\text { External } \\
\text { Storage }\end{array}$ & SQLite & Network \\
\hline File Type & $\begin{array}{l}\text { Key-Value pairs of } \\
\text { primitive data stored in } \\
\text { light-weight XML format }\end{array}$ & $\begin{array}{l}\text { Files of } \\
\text { different } \\
\text { formats. } \\
\text { Developer } \\
\text { based, no } \\
\text { restriction }\end{array}$ & $\begin{array}{l}\text { Files of } \\
\text { different } \\
\text { formats. No } \\
\text { restriction }\end{array}$ & $\begin{array}{l}\text { SQLite format (.db). } \\
\text { Compact single cross- } \\
\text { platform file }\end{array}$ & $\begin{array}{l}\text { Config and } \\
\text { network based } \\
\text { files mainly. No } \\
\text { restriction }\end{array}$ \\
\hline $\begin{array}{l}\text { Data } \\
\text { Type }\end{array}$ & $\begin{array}{l}\text { Boolean, float, int, long, } \\
\text { strings }\end{array}$ & $\begin{array}{l}\text { Complicated } \\
\text { data structures } \\
\text { allowed }\end{array}$ & $\begin{array}{l}\text { Complicated } \\
\text { data structures } \\
\text { allowed }\end{array}$ & $\begin{array}{l}\text { SQLite supported data } \\
\text { types }\end{array}$ & $\begin{array}{l}\text { Complicated data } \\
\text { structures allowed }\end{array}$ \\
\hline Location & $\begin{array}{l}\text { /data/data/com.android.phon } \\
\text { e/shared_prefs }\end{array}$ & $\begin{array}{l}\text { /data/data } \\
\text { subdirectory }\end{array}$ & $\begin{array}{l}/ \mathrm{mnt} / \mathrm{sdcard} \text { or } \\
\text { emulated SD } \\
\text { card on } \\
/ m n t / e m m c\end{array}$ & $\begin{array}{l}\text { internal storage } \\
/ \text { data/data/<packageNa } \\
\text { me>/databases }\end{array}$ & $\begin{array}{l}\text { Depends on } \\
\text { network settings, } \\
\text { info from log files } \\
\text { in data/data/files }\end{array}$ \\
\hline $\begin{array}{l}\text { Access } \\
\text { Level }\end{array}$ & Owner can access & $\begin{array}{l}\text { Developer } \\
\text { controlled } \\
\text { unless owner } \\
\text { has root access }\end{array}$ & $\begin{array}{l}\text { Owner can } \\
\text { access MS } \\
\text { FAT32 file } \\
\text { system, no } \\
\text { security } \\
\text { mechanism }\end{array}$ & $\begin{array}{l}\text { Encrypted unless } \\
\text { owner has root access }\end{array}$ & Network level \\
\hline $\begin{array}{l}\text { Forensic } \\
\text { Use }\end{array}$ & Rich source of forensic data & $\begin{array}{l}\text { Rich source of } \\
\text { forensic data if } \\
\text { root access }\end{array}$ & $\begin{array}{l}\text { Rich source of } \\
\text { forensic data }\end{array}$ & $\begin{array}{l}\text { Rich source of forensic } \\
\text { data }\end{array}$ & $\begin{array}{l}\text { Forensic data } \\
\text { from Java.net and } \\
\text { android.net }\end{array}$ \\
\hline
\end{tabular}

\subsection{Viber}

Viber is a cross-platform instant messaging application available for Symbian, Asha, Windows Mobile, Android, iOS and Blackberry operating systems. Viber application is developed by four Israeli and Belarusian partners; Talmon Marco, Igor Magazinnik, Sani Maroli and Ofer Smocha in 2010 [5]. Viber is used for making phone calls and send text messages to contacts using Viber application. WhatsApp uses $\mathrm{WiFi}$ or mobile internet plan for communicating with other users. Viber is available for free for its registered users. Viber has nearly 600 million registered users. Now, Viber Desktop is launched enabling user to install Viber application on desktop PC and use it for communicating other users with Viber on any device [6]. Viber is also considered an important application from usage perspective and hence, we have included it in our research for conducting cyber forensic analysis.

\subsection{Features \& Characteristics \\ Comparison of WhatsApp and Viber}

In this subsection, we present features and characteristics of WhatsApp and Viber application. Table 2 shows feature comparison of WhatsApp and Viber. Table 3 shows characteristic comparison of WhatsApp and Viber.Figure 1 and Figure 2 show annual population growth of registered users on WhatsApp and Viber applications respectively [7] [8].

Table 2. Feature Comparison of WhatsApp and Viber

\begin{tabular}{|l|c|c|}
\hline & WhatsApp & Viber \\
\hline Text Chat & $\checkmark$ & $\checkmark$ \\
\hline Send \& Receive Videos & $\checkmark$ & $\checkmark$ \\
\hline Send \& Receive Audio & $\checkmark$ & $\checkmark$ \\
\hline Group Chat & & \\
\hline & $\checkmark$ & $\checkmark$ \\
Sharing V-Cards \& & & \\
Contact Information & $\checkmark$ & $\checkmark$ \\
\hline & & \\
Free Voice Calling & & \\
\hline
\end{tabular}




\begin{tabular}{|l|c|c|}
\hline Free Texting & $\checkmark$ & $\checkmark$ \\
\hline Free Video Calling & $\boldsymbol{}$ & $\checkmark$ \\
\hline Location Data & $\checkmark$ & $\checkmark$ \\
\hline Desktop Compatibility & $\checkmark$ & $\checkmark$ \\
\hline
\end{tabular}

Table 3. Characteristic Comparison of WhatsApp and Viber

\begin{tabular}{|c|c|c|c|c|}
\hline Characteristics & \multicolumn{2}{|c|}{ WhatsApp } & \multicolumn{2}{|c|}{ Viber } \\
\hline \multirow{5}{*}{ Supported OS } & $\mathrm{iOS}$ & $\checkmark$ & $\mathrm{iOS}$ & $\checkmark$ \\
\hline & Android & $\checkmark$ & Android & $\checkmark$ \\
\hline & $\begin{array}{l}\text { Windows } \\
\text { Phone }\end{array}$ & $\checkmark$ & $\begin{array}{l}\text { Windows } \\
\text { Phone }\end{array}$ & $\checkmark$ \\
\hline & BlackBerry & $\checkmark$ & BlackBerry & $\checkmark$ \\
\hline & Symbian & $\checkmark$ & Symbian & $\checkmark$ \\
\hline Price & \multicolumn{2}{|c|}{$\begin{array}{l}\text { First year free } \\
\text { usage, later } \\
\text { subscription USD } \\
0.99 \text { per year }\end{array}$} & \multicolumn{2}{|l|}{ Free } \\
\hline Emoticons & \multicolumn{2}{|c|}{$\begin{array}{l}\text { Standard Emoji } \\
\text { keyboard }\end{array}$} & \multicolumn{2}{|c|}{$\begin{array}{l}\text { Custom emoticons } \\
\text { and stickers }\end{array}$} \\
\hline Group Chat & \multicolumn{2}{|c|}{100 Participants } & \multicolumn{2}{|c|}{100 Participants } \\
\hline Backup Restore & \multicolumn{2}{|c|}{ Available } & \multicolumn{2}{|c|}{$\begin{array}{l}\text { Only text backup } \\
\text { available }\end{array}$} \\
\hline Reported Users & \multicolumn{2}{|c|}{$\approx 900$ million users } & \multicolumn{2}{|c|}{$\approx 600$ million users } \\
\hline
\end{tabular}

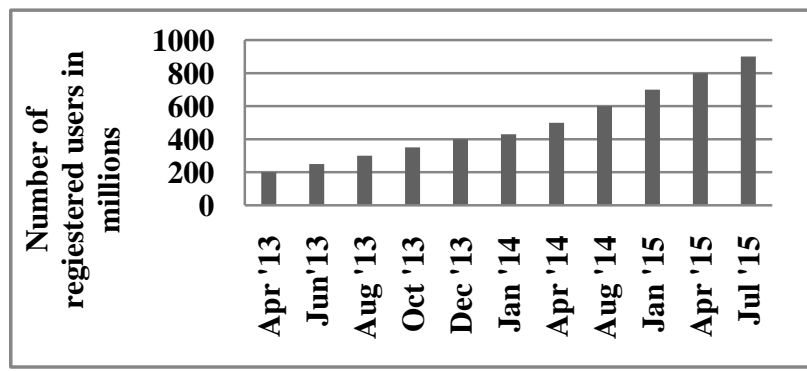

Figure 1: Global population growth of registered users on WhatsApp

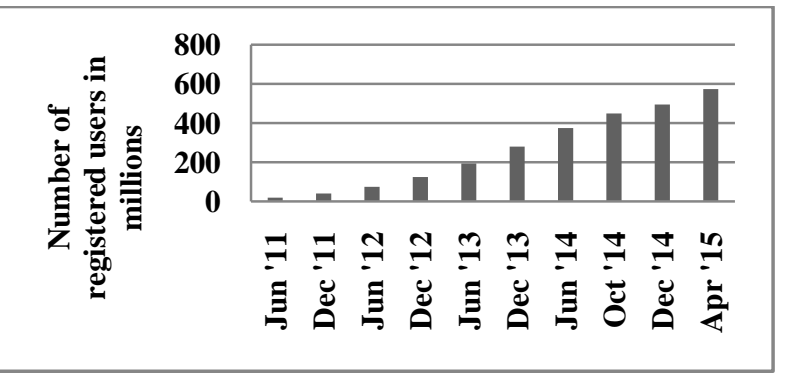

Figure 2: Global population growth of registered users on Viber

\section{DATABASE SCHEMA OF WHATSAPP AND VIBER ON ANDROID}

\subsection{Forensic Analysis of Database Schema of WhatsApp on Android}

WhatsApp artifacts such as contacts, messages and attachments can be valuable to examiners looking for recovering evidences during investigation. The key artifacts that need to be found during investigating WhatsApp on Android are SQLite databases msgstore.db and wa.db. The $m s g s t o r e . d b$ contains details of any chat conversation between user and their contacts. The $w a . d b$ stores information of user's contact list. Figure 3 shows WhatsApp Database schema containing msgstore.db and wa.db. Both databases can be found under the database folder at the following defined locations:

msgstore. $d b \rightarrow /$ data/data/com.whatsapp/database/msgstore.db $w a . d b \rightarrow /$ data/data/com.whatsapp/database/wa.db.

The msgstore.db is a SQLite database containing two tables namely chat_list and messages. The msgstore.db database contains contacts numbers, message contacts, message status, timestamps, geolocation details of senders and attachments. The attachments have their own table entry linked with message content including thumbnail and link of the attachment. In messages table, messages sent or received from contacts are stored. The $w a . d b$ database contains a complete listing of WhatsApp user contacts including phone numbers, display name, time stamp [9]. WhatsApp stores a copy of msgstore.db and wa.db on memory (flash/SD card) of mobile device at the following location:

\section{/sdcard/whatsapp/databases/msgstore.db.cypt}

However, msgstore.db and wa.db databases are encrypted and therefore must be decrypted for analysis by rooting the mobile device after acquisition [9].

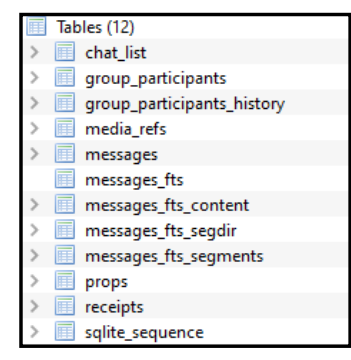

a) msgstore.db Schema

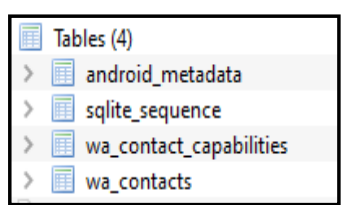

b) wa.db Schema
Figure 3: Snapshot of WhatsApp Database Schema in SQLite Browser

\subsection{Forensic Analysis of Database Schema of Viber on Android}

Viber artifacts relevant to forensic investigations are stored within SQLite databases. To access important Viber artifacts, analyst must root or get a physical acquisition of the Android device. Viber artifacts on Android are stored found at the following locations:

/data/data/com.viber.voip/databases/viber_data

/data/data/com.viber.voip/databases/viber_messages 
These databases store details on the Viber user's contacts, messages and attachments sent and received through Viber application.

- Viber Contacts - User contacts in Viber are stored within the viber_data SQLite database.

- Viber Messages - Given that Viber is an IM with call capability, it's likely that the most valuable evidence will be found in the conversation.

- Viber Attachments - Viber also supports the transfer of photos. Photos - sent from either the camera or gallery are stored on the mobile device. Attachment also includes a "description" entered by the sender of the attachment.

Figure 4 shows a snapshot of database tables of Viber application available through SQLite Browser and Cerbero.

Further, Table 4 presents collective list of WhatsApp and Viber application with available databases along with tables present in corresponding databases [10].

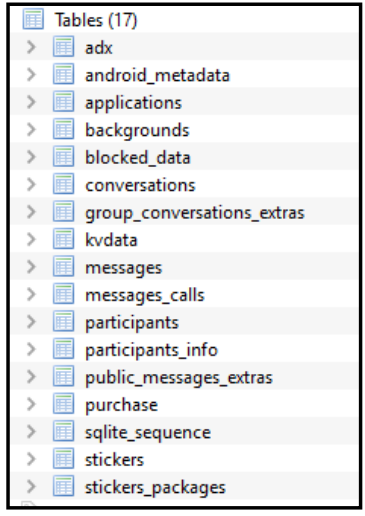

\begin{tabular}{|l|}
\hline android_metadata \\
conversations \\
sqlite_sequence \\
group_conversations_extras \\
participants \\
participants_info \\
messages \\
messages_calls \\
public_messages_extras \\
\hline
\end{tabular}

(a) Snapshot from SQLite Browser (b) Snapshot from Cerbero

Figure 4: Database Tables in Viber Application

Table 4. Application Database and Table name

\begin{tabular}{|l|l|l|}
\hline \multirow{4}{*}{ Application } & \multicolumn{1}{|c|}{ File Name } & Table Name \\
\hline \multirow{5}{*}{ Viber } & msgstore.db & $\begin{array}{l}\text { messages } \\
\text { chat_list }\end{array}$ \\
\cline { 2 - 4 } & wa.db & $\begin{array}{l}\text { wa_contacts } \\
\text { sqlite_sequence }\end{array}$ \\
\cline { 2 - 3 } & viber_call_log.db & Viber_call_log \\
\cline { 2 - 3 } & viber_data & $\begin{array}{l}\text { android_metadata } \\
\text { phonebook raw } \\
\text { contact } \\
\text { phonebook contact }\end{array}$ \\
& $\begin{array}{l}\text { phonebook data } \\
\text { Viber numbers } \\
\text { Calls }\end{array}$ \\
\hline
\end{tabular}

\begin{tabular}{|l|l}
\hline viber_messages & $\begin{array}{l}\text { android_metadata } \\
\text { messages' } \\
\text { sqlite_sequence } \\
\text { threads } \\
\text { participants }\end{array}$
\end{tabular}

\section{IMPLEMENTATION OF FORENSIC} PROCEDURES

In this paper, we implement forensic procedures to determine available evidences which might be helpful in determining results during forensic analysis. We have targeted the scope of our research to WhatsApp and Viber only for sole reason of their prevalent use. For analysis, we have taken a sample device Micromax Canvas A74 smartphone running Android 4.2.2 JellyBean operating system as acquired device. List of required software and tools for forensic procedures are tabulated in Table 5 below:

Table 5. List of Application Required for Forensic Procedures

\begin{tabular}{|l|l|l|}
\hline Application & Available at & Paid/Free \\
\hline $\begin{array}{l}\text { Titanium } \\
\text { Aackup } \\
\text { Application }\end{array}$ & Google Play Store & Free \\
\hline FramaRoot & www.framaroot.net & Free \\
\hline RootChecker & Google Play Store & Free \\
\hline $\begin{array}{l}\text { WhatsApp } \\
\text { Viewer }\end{array}$ & $\begin{array}{l}\text { http://andreas- } \\
\text { mausch.github.io/whatsapp- } \\
\text { viewer/ }\end{array}$ & Free \\
\hline $\begin{array}{l}\text { Cerbero } \\
\text { Profiler 2.4 }\end{array}$ & $\begin{array}{l}\text { http://cerbero.io /profiler/ } \\
\text { FQLite } \\
\text { Browser }\end{array}$ & sqlitebrowser.org/ Trial \\
\hline
\end{tabular}

We will present stepwise methods which were implemented during our research to determine artifacts. In subsection 4.1, initial prerequisite tasks are performed on mobile device such rooting the mobile device and backing up of required application. In subsection 4.2, we focus on WhatsApp and Viber applications.

\subsection{Initial Pre-requisite Tasks on Mobile Device}

Step 1: Mobile device is rooted using Android rooting application FramaRoot.

Table 6 shows detailed methods of rooting the mobile device using FramaRoot application.

Further, we can verify that mobile device is successfully rooted or not by installing RootChecker Application and running it. However, this verification is optional method. 
Step 2: Backup of messages using Titanium Backup Application

After rooting mobile device, backup of message are done using Titanium Backup Application. Manual setting of Titanium Backup is done to corresponding application either WhatsApp or Viber.

Step 3: Identify and locate zip folder within Titanium Backup folder on SD card location of mobile device. Copy the identified zipped folder from Titanium Backup folder to desktop PC after connecting mobile device to desktop PC. (For WhatsApp, zipped folder starts with name com.whatsapp and for Viber, zipped folder starts with com.viber.voip)

Step 4: Backup Extracted from Titanium Backup Application on Desktop PC.

Table 6. Rooting Mobile Device using FramaRoot Application

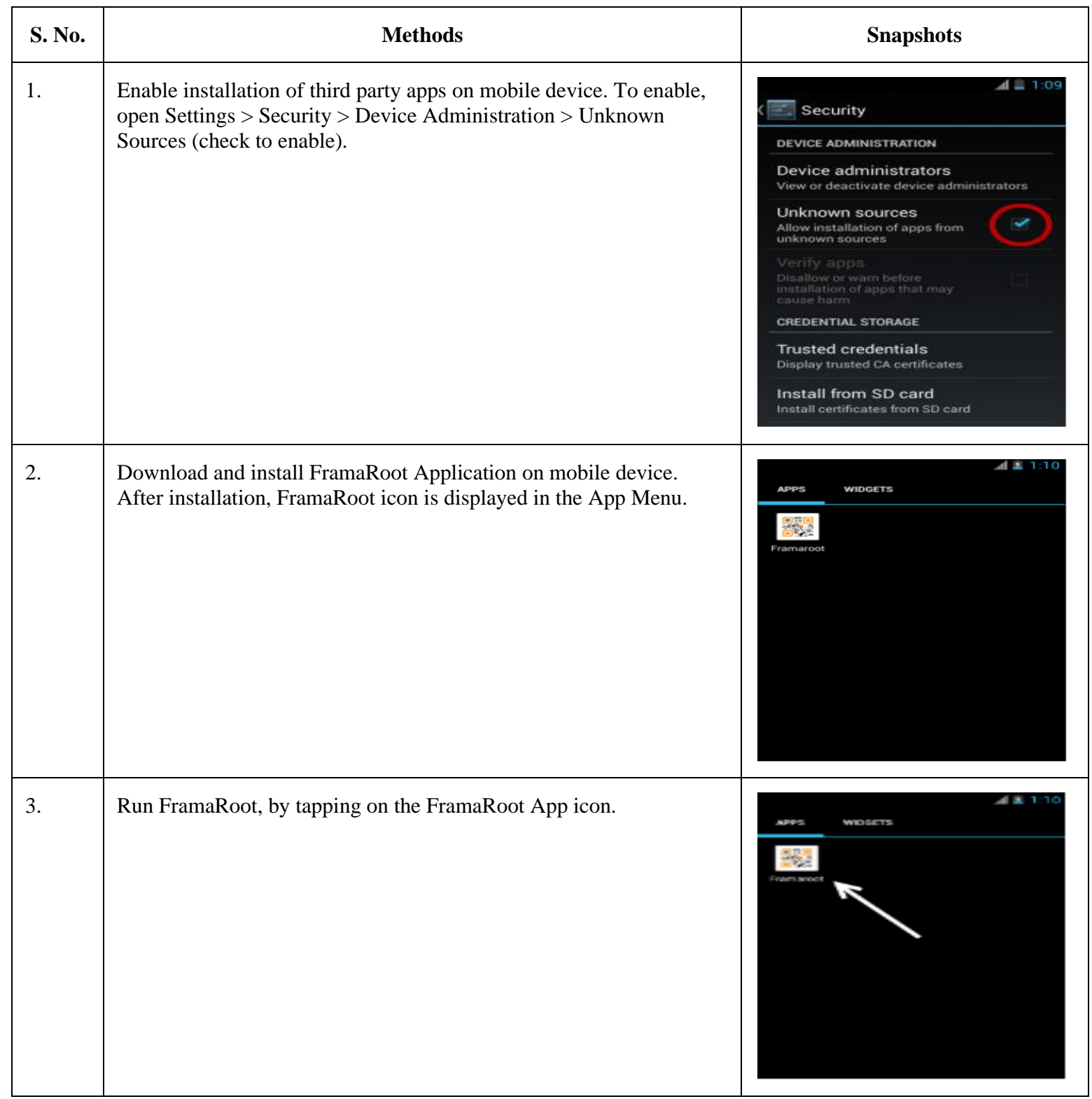




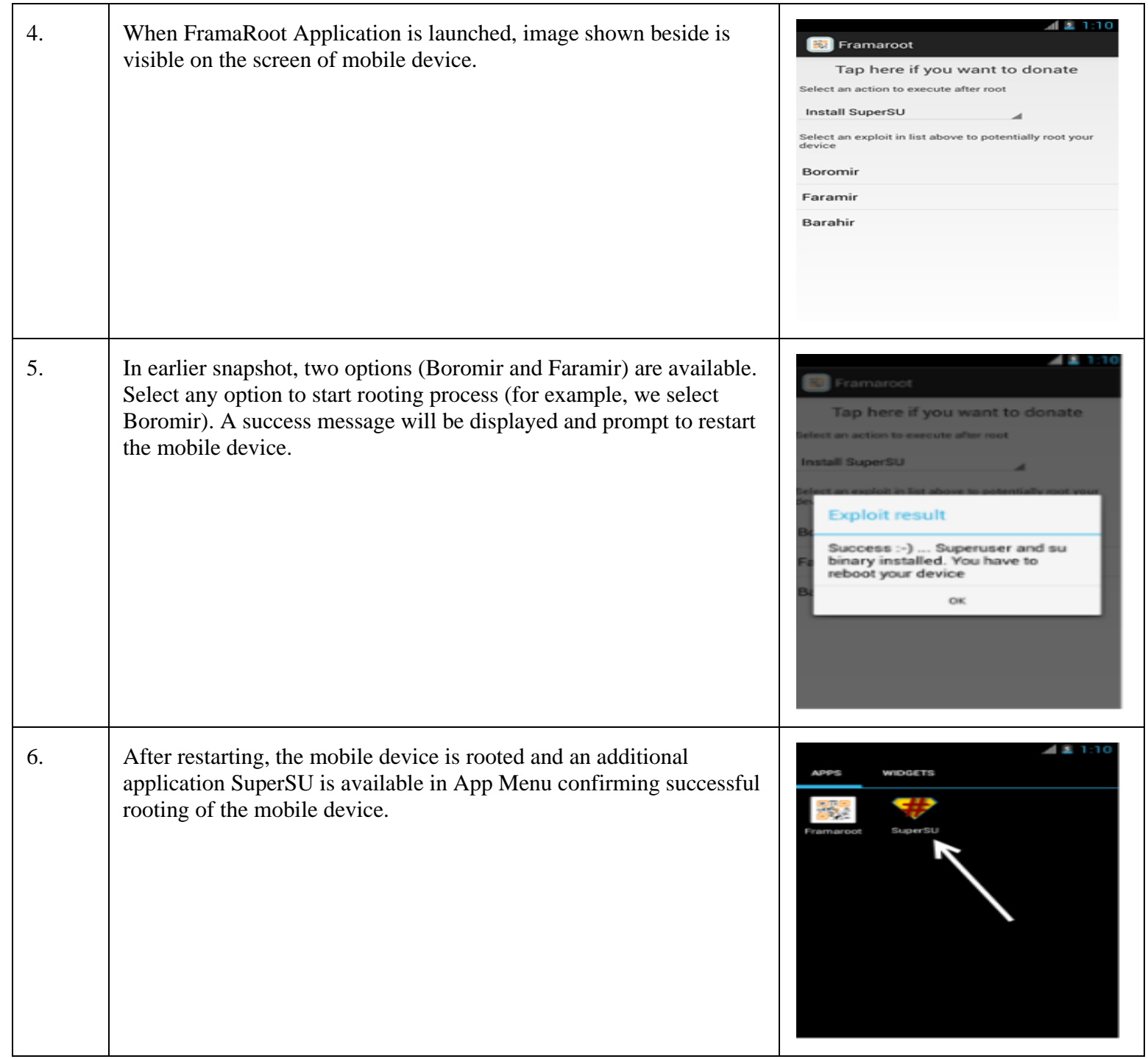

After copying the zipped folder, we unzipped the required folder. Figure 5 shows required directory structure of copied folder from com.whatsapp (WhatsApp backup is done using Titanium Backup Application) and Figure 6 shows required directory structure of copied folder from com.viber.voip. In Figure 5, msgstore.db and wa.db files as encircled in figure are required for forensic analysis (applicable for WhatsApp) whereas in Figure 6, viber_data and viber_messages files as encircles in figure are required for forensic analysis (applicable for Viber).

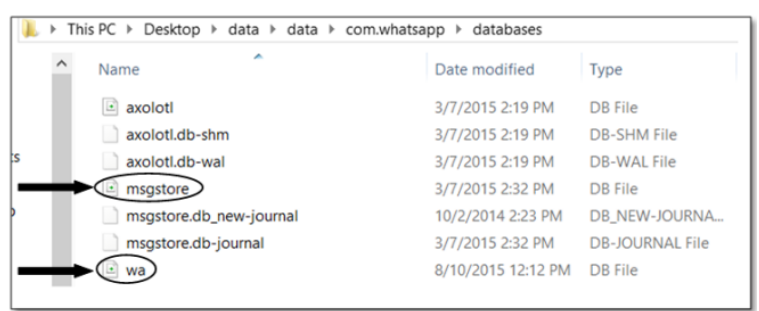

Figure 5: Snapshot of Unzipped com.whatsapp Folder Directory

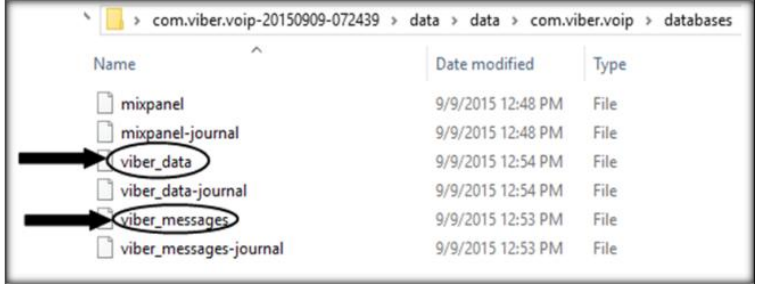

Figure 6: Snapshot of Unzipped com.viber.voip Folder Directory

\subsection{Forensic Analysis of WhatsApp and Viber}

In this subsection, we focus on WhatsApp application for forensic analysis to determine artifacts from the mobile device. After taking backup of WhatsApp application data, tools like WhatsXtract, SQLite browser, WhatsApp Viewer etc. are required to determine artifacts. These tools present artifacts to the analyst in readable and presentable format. WhatsApp Viewer is a small tool to display chats from WhatsApp files such as msgstore.db.crypt5, msgstore.db.crypt7 and msgstore.db.crypt8. Among all available tools, WhatsApp Viewer is most convenient and 
simple to use because of the following features listed below [11].

- View WhatsApp chats on PC

- $\quad$ Phone backup

- Conveniently read old conversations without pressing "load older messages"

- $\quad$ Search all messages

- No need to install Python, SQLite or additional libraries

- Small application, no dependencies, no need to install

4.2.1 For analysis of WhatsApp artifacts, we have used WhatsApp Viewer. Figure 7 shows snapshot of WhatsApp messages in WhatsApp viewer. Analyst can browse through available contacts and read messages exchanged between user of mobile device and contacts.

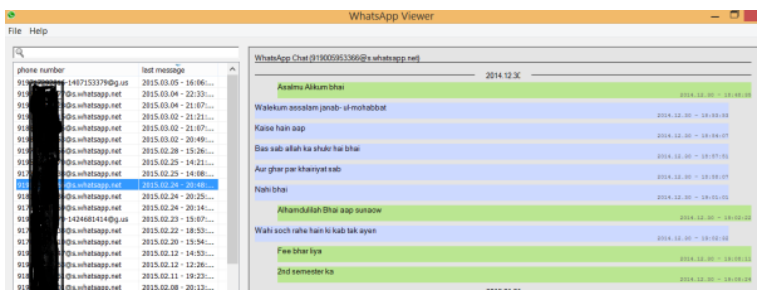

Figure 7: Snapshot of WhatsApp Viewer

4.2.2 For analysis of Viber artifacts, we have used Cerbero and SQLite Browser. The unzipped folder com.viber.voip obtained from Titanium Backup Application contains viber_messages and viber_data. Figure 8 and Figure 9 shows snapshot of Viber artifacts in viber_messages and viber_data respectively available in Cerbero.

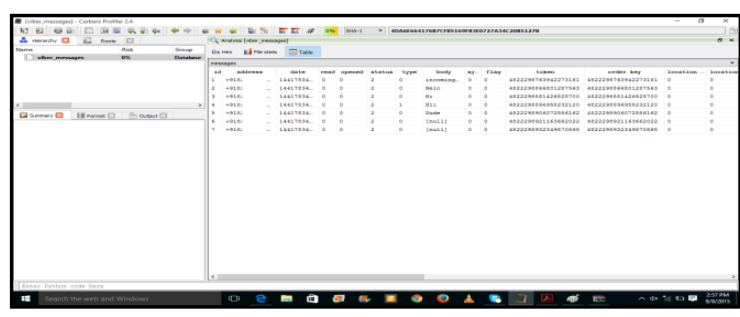

Figure 8: Snapshot of Cerbero displaying Viber artifacts obtained from viber_messages

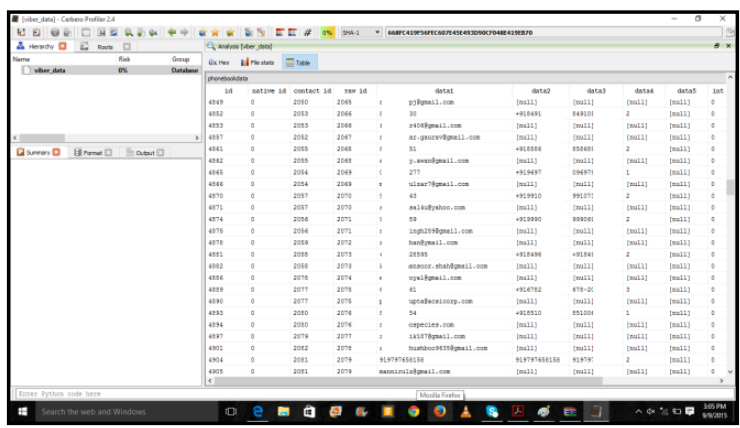

Figure 9: Snapshot of Cerbero displaying Viber artifacts obtained from viber_data

We have also studied Viber artifacts from files viber_message and viber_data using SQLite Browser. Figure 10 and Figure 11 shows snapshot of Viber artifacts in viber_messages and viber_data respectively available in SQLite Browser. Although, we observe differences in displayed artifacts in Cerbero and SQLite Browser. For instance, database schema of Viber is not available in Cerbero, however, displayed in SQLite Browser. Location of sender is not available in SQLite Browser, however, it is available in Cerbero.

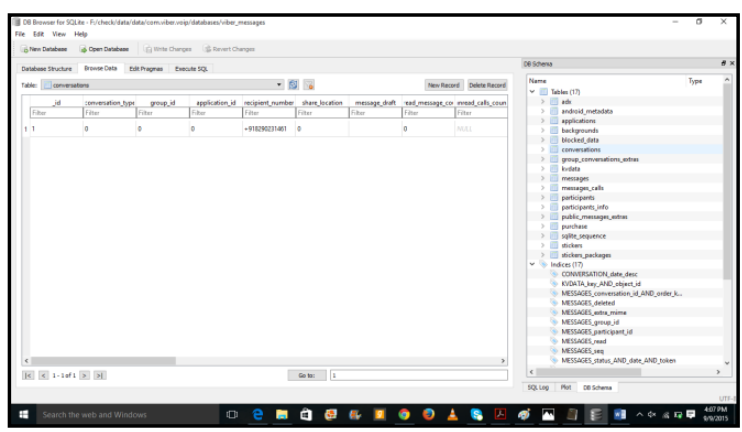

Figure 10: Snapshot of SQLite Browser displaying Viber artifacts obtained from viber_messages

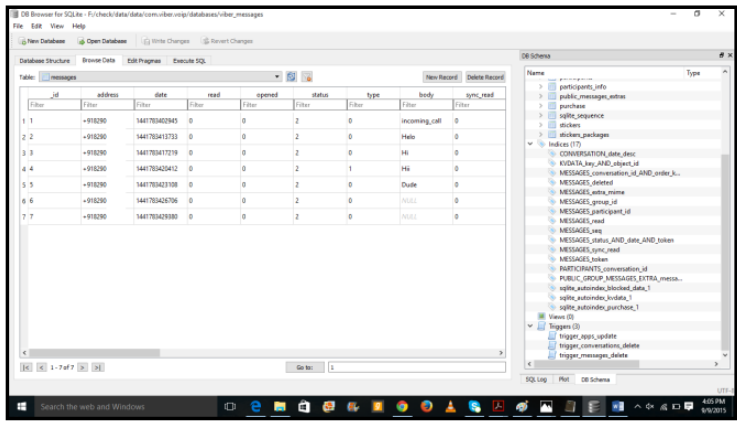

Figure 11: Snapshot of SQLite Browser displaying Viber artifacts obtained from viber_data

\section{RESULTS OF RESEARCH FINDINGS AND FORENSIC ANALYSIS}

In this section, we present our research findings based on our analysis for WhatsApp and Viber. Table 7 presents the research findings of forensic analysis for WhatsApp. In this table, different artifacts such as phone numbers, messages, media files etc. have been obtained. However, these artifacts are encrypted and thus unreadable to analyst. When we perform our analysis after rooting the mobile device, these artifacts are obtained in readable and presentable form. Legends used in Table 6 are shown below with their intended meaning.

Table 7. Research Findings of Forensic Analysis for WhatsApp

\begin{tabular}{|l|c|c|}
\hline & $\begin{array}{l}\text { Unrooted Mobile } \\
\text { Device }\end{array}$ & $\begin{array}{l}\text { Rooted Mobile } \\
\text { Device }\end{array}$ \\
\hline msgstore.db & $\checkmark \square$ & $\checkmark$ \\
\hline wa.db & $x$ & $\checkmark$ \\
\hline Phone Numbers & $\checkmark \square$ & $\checkmark$ \\
\hline Messages & $\checkmark \square$ & $\checkmark$ \\
\hline Media Files & $\checkmark \square$ & $\checkmark$ \\
\hline
\end{tabular}




\begin{tabular}{|l|c|c|}
\hline Contact Cards & $\checkmark \square$ & $\checkmark$ \\
\hline Location & $\checkmark \square$ & $\checkmark$ \\
\hline SQL queries & $\checkmark \square$ & $\checkmark$ \\
\hline Profile Pictures & $\checkmark$ & $\checkmark$ \\
\hline Logs & $x$ & $\checkmark$ \\
\hline $\begin{array}{l}\text { Directory } \\
\text { Structure }\end{array}$ & $x$ & $\checkmark$ \\
\hline Deleted Messages & $x$ & $\checkmark$ \\
\hline WhatsApp Call & $x$ & $\checkmark$ \\
\hline
\end{tabular}

Legends used in Table 7

$$
\begin{aligned}
& \checkmark \quad \text {......Found Encrypted } \\
& \times \quad \ldots \ldots \ldots . . \text { Not Found } \\
& \checkmark \text {.......... Found }
\end{aligned}
$$

Table 8 presents the research findings of forensic analysis for Viber. Both files viber_data and viber_messages are analyzed and results are presented. Table 8 shows different artifacts such as Viber numbers, messages, number of calls etc. have been obtained.

Table 8. Research Findings of Forensic Analysis for Viber

\begin{tabular}{|l|l|}
\hline \multicolumn{1}{|c|}{$\begin{array}{c}\text { Artifacts Found in } \\
\text { viber_data }\end{array}$} & \multicolumn{1}{c|}{$\begin{array}{c}\text { Artifacts Found in } \\
\text { viber_messages }\end{array}$} \\
\hline Viber Numbers & Messages to Viber users \\
\hline Total number of calls made & $\begin{array}{l}\text { Phone numbers of the } \\
\text { recipient of messages }\end{array}$ \\
\hline $\begin{array}{l}\text { Phone numbers at which } \\
\text { calls were made }\end{array}$ & $\begin{array}{l}\text { Phone numbers of the sender } \\
\text { of messages }\end{array}$ \\
\hline Duration of each calls & $\begin{array}{l}\text { Time and date of sent and } \\
\text { received messages }\end{array}$ \\
\hline Time and date of calls & $\begin{array}{l}\text { Message statistics for each } \\
\text { contact }\end{array}$ \\
\hline
\end{tabular}

The scope of this research is focused on obtaining artifacts from Android instant messengers (specifically Viber and WhatsApp). These artifacts such as text messages, audio calls to any suspicious contact, image/video or location coordinates etc. are used in investigation for providing digital evidence that is acceptable in court of law against any criminal activity. These research findings help in forensic investigation as proofs for prosecuting a criminal who has committed any crime.

\section{CONCLUSION}

In this paper, we have presented forensic analysis of WhatsApp and Viber Android applications. We performed implementation of forensic procedures for WhatsApp and Viber applications. We performed comparative study of database design and features available in WhatsApp and Viber applications. The aim was to determine key artifacts present in memory of mobile devices using available tools and software. We have tabulated our research findings obtained from WhatsApp and Viber applications. The research findings include artifacts that help forensic investigators and investigation agencies during any criminal incident and can be used as evidence in court of law. In future, recovery of artifacts of instant messenger applications residing on RAM of mobile device can be a part of our research scope.

\section{ACKNOWLEDGMENTS}

We thank our friends for motivation and support in presenting this paper.

\section{REFERENCES}

[1] [Online]https://en.wikipedia.org/wiki/Android_(operatin g_system)

[2] Thakur. S. N. 2013 Forensic Analysis of WhatsApp on Android Smartphones. University Of New Orleans

[3] [Online] http://www.whatsapp.com

[4] [Online] http://blog.whatsapp.com/

[5] [Online] https://en.wikipedia.org/wiki/Viber

[6] [Online] http://www.viber.com/en/

[7] [Online] http://www.statista.com/statistics/316414/vibermessenger-registered-users/

[8] [Online] http://www.statista.com/statistics/260819/number-ofmonthly-active-whatsapp-users/

[9] [Online] http://iloapp.cybersecurityspecialist.com/blog/blog?Hom e\&category $=5$

[10] Mahajan A., Dahiya M. and Sanghvi H. 2003. Forensic Analysis of Instant Messenger Applications on Android Devices. International Journal of Computer Applications (April 2013), 0975 - 8887.

[11] [Online]http://andreas-mausch.github.io/whatsappviewer/ 